\title{
ANALYSIS OF CORONAVIRUS TRANSCRIPTION REGULATION
}

\author{
Myungsoo Joo and Shınjı Makıno \\ Department of Microbiology \\ The University of Texas \\ Austın, Texas
}

\begin{abstract}
Insertion of an intergenic region from murıne coronavirus mouse hepatitis virus (MHV) into an MHV defective interfering (DI) RNA led to transcription of subgenomic DI RNA in helper virus-infected cells Using this system we studied how two intergenic regions positioned in close proximity affected subgenomic RNA synthesis When two intergenic regions were separated by more than $100 \mathrm{nt}$, slightly less of the larger subgenomic DI RNA (synthesized from the upstream intergenic region) was made, this difference was significant when the intergenic region separation was less than about 35 nucleotides Deletion of sequences flanking the two intergenic regions inserted in close proximity did not affect transcription No significant change in the ratio of the two subgenomic DI RNAs was observed when the sequence between the two intergenic regions was altered Removal of the downstream intergenic region restored transcription of the larger subgenomic DI RNA These results demonstrated the downstream intergenic sequence was suppressing subgenomic DI RNA synthesis from the upstream intergenic region
\end{abstract}

\section{INTRODUCTION}

Mouse hepatitis virus (MHV) is the coronavirus prototype MHV contains a singlestranded, positive sense RNA of approximately $31 \mathrm{~kb}^{13}$ In MHV-infected cells, seven to eight species of virus-specific mRNAs are synthesized, they are named mRNA 1 to 7 according to decreasing order of size ${ }^{4}{ }^{5}$ The $5^{\prime}$ end of the MHV genomic RNA and subgenomic mRNAs starts with a 72-77 nucleotide-long leader sequence ${ }^{6} 7$ The mRNA body sequences begin from a consensus sequence (UCUAAAC, or a very similar sequence) in the intergenic region, which is located upstream of each MHV gene ${ }^{6} 7$ The intergenic region preceding gene 7 (gene 7 encodes the nucleocapsid protein) carries the same 18 
nucleotide-long sequence (AAUCUAAUCUAAACUUUA) found at the $3^{\prime}$ region of the genomic leader sequence ${ }^{8}$.

A system that exploits defective interfering (DI) RNAs of MHV for the study of coronavirus transcription is established ${ }^{9}$. One study using this system demonstrated that the sequences flanking the intergenic region preceding gene 7 do not play a role in subgenomic DI RNA transcription ${ }^{10}$. However, studies of an MHV mutant virus ${ }^{11}$ and bovine coronavirus (BCV) subgenomic $m \mathrm{mNAs}^{12}$ raise the possibility that sequence(s) outside of the intergenic consensus sequence may affect coronavirus transcription. From these studies we hypothesized that two coronavirus intergenic consensus sequences that are located in close proximity may interact in such a way that the presence of a downstream consensus sequence may inhibit transcription of subgenomic mRNA from an upstream consensus sequence. We examined this possibility, and present new aspects of coronavirus transcription regulation.

\section{MATERIALS AND METHODS}

\section{Viruses and Cells}

The plaque-cloned A59 strain of MHV (MHV-A59) was used as a helper virus. Mouse DBT cells were used for growth of viruses.

\section{DNA Construction}

A procedure based on recombinant polymerase chain reaction (PCR) was employed for site-directed mutagenesis ${ }^{13}$. Construction of various plasmids will be described elsewhere.

\section{RNA Transcription and Transfection}

Plasmid DNAs were linearized by Xba I digestion and transcribed with T7 RNA polymerase as previously described ${ }^{14}$. The lipofection procedure was used for RNA transfection as previously described ${ }^{9}$.

\section{Primer Extension}

The oligonucleotides were $5^{\prime}$-end labeled with $\left[\gamma^{32} \mathrm{P}\right]$ ATP with polynucleotide kinase $^{15}$. Poly (A) containing RNAs were used for primer extension analysis as described previously ${ }^{16}$. Reaction products were analyzed on $6 \%$ polyacrylamide gels containing $7 \mathrm{M}$ urea.

\section{PCR and Direct Sequencing of the PCR Products}

Primer extension products were purified from the gel and amplified by PCR under the same condition described above. The gel-purified RT-PCR products were separated by agarose gel electrophoresis. Direct PCR sequencing was performed according to the procedure established by Winship ${ }^{17}$. 


\section{RESULTS}

\section{The Effect of Two Proximally Inserted Intergenic Regions on MHV Subgenomic DI RNA Transcription}

In an attempt to gauge the effect of a downstream intergenic region on its upstream neighbor, we measured the synthesis of two subgenomic DI RNAs that were transcribed from two proximally inserted intergenic consensus sequences. We constructed a series of MHV DI cDNAs, each of which contained two intergenic regions in the same parental clone, MHV DI RNA-derived cDNA clone MT1/174 ${ }^{10}$. All clones contained an insertion upstream of the 18 nucleotide-long intergenic region of MT1/174. The inserted sequence consisted of the 18 nt-long intergenic region preceding gene 7 attached to varying lengths of downstream sequence and a few nucleotides from the $3^{\prime}$-end, which were generated by construction procedures. Therefore, these newly constructed DI cDNA clones bore two $18 \mathrm{nt}$-long intergenic regions; most of the sequences between the two intergenic regions derived from downstream of the intergenic region between genes 6 and 7. We named these DI cDNAs according to the distance between the first nucleotide of the upstream intergenic region and the first nucleotide of the downstream intergenic region. In MS124, the first nucleotide of the downstream intergenic region is located $124 \mathrm{nt}$ from the first nucleotide of the upstream intergenic region.

We used primer extension analysis to examine the quantities of the two subgenomic DI RNAs in the mutants with similar size subgenomic DI RNAs. The 5'-end labeled oligonucleotide, which specifically binds with genomic and subgenomic DI RNAs, but not to helper virus mRNAs, hybridized with intracellular RNA species and the hybridized primer was extended by reverse transcriptase. Primer extension products were then analyzed by electrophoresis on sequencing gels (Fig. 1). Large amounts of a primer extension product corresponding to a smaller subgenomic DI RNA, synthesized from the downstream intergenic region, were made in MS23-, MS29- and MS36-replicating cells (Fig. 1A). We frequently observed a minor primer extension product, which migrated as if it were 5 nucleotides longer than the major primer extension product (Fig. 1, shown by the open triangle). The amount of a primer extension product corresponding to a larger subgenomic

Figure 1. Primer extension analysis of subgenomic DI RNAs. The $5^{\prime}$-end labeled oligonucleotide was hybridized with intracellular RNAs and extended with reverse transcriptase. The products were electrophoresed on sequencing gels. Panels A and B represent two independently electrophoresed gels The arrows and arrowheads indicate the larger subgenomic DI RNA primer extension products and the smaller subgenomic DI RNA primer extension products, respectively. The minor bands indicated by the open triangles are the smaller subgenomic DI RNAs which contained three UCUAA repeats at the leader-body junction.
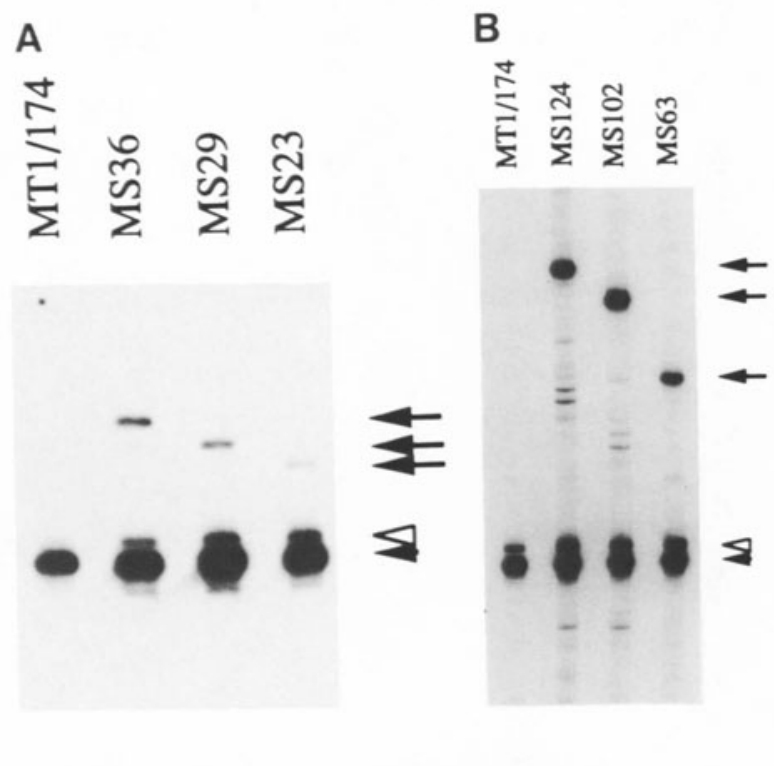
DI RNA, produced from the upstream intergenic region, was significantly reduced (Fig. 1A). Direct sequencing of PCR products demonstrated that the larger and the smaller primer extension products contained the expected structure of the larger and the smaller subgenomic DI RNA, respectively. All the subgenomic DI RNAs contained two repeats of UCUAA at the leader-body junction site. The minor primer extension products, which migrated slightly slower than the major primer extension product of the smaller subgenomic DI RNAs, exhibited structures that were similar to the smaller subgenomic DI RNAs, except that they contained three UCUAA repeats. These analyses demonstrated that transcription of the larger subgenomic DI RNA was inhibited when two intergenic regions were inserted within 23 to 36 nucleotides of each other.

We examined the effect of the length of the "gap" between the two intergenic sites on inhibition of the larger subgenomic DI RNA transcription. The amounts of the larger and the smaller subgenomic DI RNAs of MS124, MS102 and MS63 were compared (Fig. 1B). Primer extension analysis and direct sequencing of PCR products of the primer extension products demonstrated that more of the larger subgenomic DI RNAs (shown by the arrows in Fig. 1B) were synthesized in MS124-, MS102 and MS63-replicating cells than had been made in MS36-, MS29- and MS23- replicating cells (Fig. 1A). When two intergenic regions were separated by about 60 nucleotides, a distinct inhibition of transcription of the larger subgenomic DI RNA occurred. Of the DI RNAs that we analyzed, the degree of inhibition increased as the distance between the two intergenic regions decreased; MS23, with the shortest sequence between the two intergenic sites, demonstrated the greatest inhibition of the larger subgenomic DI RNA transcription.

\section{The Effect of Sequences Flanking the Two Inserted Intergenic Regions on Subgenomic DI RNA Transcription}

We looked for an effect of the sequences flanking the two inserted intergenic regions on subgenomic DI RNA transcription by analyzing two MS23-derived DI cDNAs, MS23 $\triangle$ DF and MS23 $\triangle$ UF. Downstream of the MS23 intergenic region, we deleted $156 \mathrm{nt}$ to create MS23 $\triangle \mathrm{DF}$. Upstream of the MS23 intergenic region we removed $0.8 \mathrm{~kb}$ to make MS23 $\Delta$ UF. Primer extension analysis and direct sequencing of the PCR products of the primer extension products demonstrated that the transcription of the large subgenomic DI RNA was inhibited in both DI RNAs (Fig. 2A). These studies demonstrated that the flanking sequences of the two inserted intergenic regions did not affect the inhibition of the larger subgenomic DI RNA's transcription.

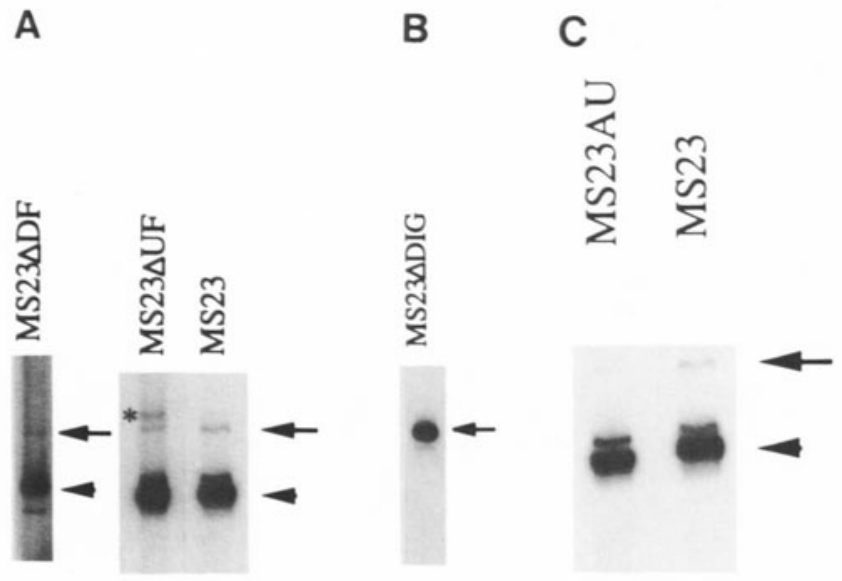

Figure 2. Primer extension analysis of subgenomic DI RNAs. The arrows and arrowheads indicate the the larger subgenomic DI RNA primer extension products and the smaller subgenomic DI RNA primer extension products, respectively. An asterisk most likely indicates a premature termination product of the genomic DI RNA primer extension product. 


\section{Investigation of a Possible Effect of the Downstream Intergenic Region on Inhibition of Transcription from the Upstream Intergenic Consensus Sequence}

To directly test the effect of the downstream intergenic region on inhibition of transcription from the upstream intergenic region we used a new construct, MS23 $\triangle \mathrm{DIG}$. This MS23-derived DI cDNA lacked the entire 18 nucleotide-long downstream intergenic region; in its place, MS23 $\triangle \mathrm{DIG}$ carried an 8 nucleotide insertion from a non-MHV sequence, which was generated through the DNA construction procedure. Northern blot analysis of MS23 $\triangle$ DIG intracellular RNA species demonstrated that the amount of MS23 $\Delta$ DIG subgenomic DI RNA was comparable to that of MT1/174 (data not shown), which synthesizes a high level of subgenomic DI RNA. Primer extension analysis of MS23 $\Delta$ DIG showed an abundance of product corresponding to the larger subgenomic DI RNA, whereas no primer extension product made from the smaller subgenomic DI RNA was seen (Fig. 2B). This data clearly demonstrated that the presence of a downstream intergenic region inhibited transcription from the upstream intergenic region.

The actual sequence of the nucleotides between the two intergenic regions might affect transcriptional efficiency of the larger subgenomic DI RNA; we tested this by changing the nucleotides between the two repeated UCUAA sequences of the intergenic regions in clone MS23, making clone MS23AU. Primer extension analysis of MS23AU revealed that transcription of the larger subgenomic DI RNA was inhibited (Fig. 2C). This experiment indicated that inhibition of transcription from the upstream intergenic region did not depend on the nucleotide sequence between the two intergenic regions, because there was significant inhibition after mutation of the "gap" between the intergenic sites. That mutation did have an effect, however, which we saw as a small increase in the inhibition of transcription from the upstream intergenic site.

\section{DISCUSSION}

In the present study, transcription of the larger of two subgenomic DI RNAs, which was synthesized from the upstream intergenic region of two closely inserted intergenic regions, was inhibited; its inhibition was caused by the presence of the downstream intergenic sequence. In the case of the gene 6-7 intergenic sequence, transcription efficiency is not affected by sequences flanking the intergenic sequence ${ }^{10}$. A contrasting exception to that, presented here, was when the flanking sequence was itself an intergenic region, and affected transcription by inhibiting the intergenic region that it flanked. Recently, we placed a transcription consensus sequence in the middle of a $0.4 \mathrm{~kb}$ fragment, which was located at a fixed position but derived from various regions of $\mathrm{MHV}$, and found that transcription of subgenomic DI RNAs varied among the DI RNA constructs (unpublished data). This data indicated that flanking sequences of the inserted intergenic region affected subgenomic DI RNA transcription efficiency. It is possible that each of the naturally occurring MHV intergenic sites is regulated in an analogous but slightly different way that depends upon flanking sequences.

Our finding explains well why a BCV subgenomic mRNA is not synthesized from the predicted intergenic consensus sequence, but is synthesized from another sequence, located 15 nucleotides downstream of the predicted intergenic consensus sequence ${ }^{12}$. The conclusions from our study also provide a reason for why it is that in MHV-S No. 8-infected cells the amount of the larger mRNA 7, which is synthesized from the upstream consensus sequence, is significantly lower than of that of the smaller mRNA 7, which is synthesized 
from the downstream consensus sequence ${ }^{11}$ The transcriptional regulation of MHV DI RNAs is most likely governed by the same mechanism as coronavirus transcription, and the data shown in the present study, therefore, sheds light directly on the understanding of the actual coronavirus transcription mechanısm

\section{ACKNOWLEDGMENTS}

We thank Young-Nam Kim for performıng some of the prelımınary work This work was supported by Public Health Service grants AI29984 and AI32591 from the National Institutes of Health, U S A

\section{REFERENCES}

1 La1, M M C , and Stohlman, S A RNA of mouse hepatitss virus J Virol 1978,26 236-242

2 Lee, H -J , Shieh, C -K , Gorbalenya, A E, Eugene, E V, La Monica, N, Tuler, J, Bagdzhadzhyan, A, and Lal, M M C The complete sequence (22 kılobases) of murıne coronavirus gene 1 encoding the putative proteases and RNA polymerase Virology 1991,180 567-582

3 Pachuk, C J, Bredenbeek, P J Zoltıck, P W, Spaan, W J M, and Weiss, S R Molecular cloning of the gene encoding the putative polymerase of mouse hepatitis virus, strain A59 Virology 1989,171 141148

4 Lal, M M C, P R Brayton, P R, Armen, R C, Patton, C D, Pugh, C, and Stohlman, S A Mouse hepatitis virus A59 mRNA structure and genetic localization of the sequence divergence from hepatotropic strain MHV-3 J Virol 1981,39 823-834

5 Leibowitz, J L , Wilhelmsen, K C , and Bond, C W The virus-specific intracellular RNA species of two murine coronaviruses MHV-A59 and MHV-JHM Virology 1981,114 39-51

6 Lai, M M C, Barıc, R S , Brayton, P R, and Stohlman, S A Characterization of leader RNA sequences on the virıon and mRNAs of mouse hepatitıs vırus, a cytoplasmıc RNA vırus Proc Natl Acad Scı USA 1984,81 3626-3630

7 Spaan, W, Delıus H Skınner, M, Armstrong, J, Rotter, P, Smeekens, S, van der Zeıjst, B A M, and Siddell,S G Coronavirus mRNA synthesis involves fusion of non-contiguous sequences EMBO J 1983,2 1939-1944

8 Shieh, C -K, Soe, L H, Makıno, S, Chang, M-F, Stohlman, S A, and La1, M M C The 5'-end sequence of the murine coronavirus genome implications for multiple fusion sites in leader-primed transcription Virology 1987,156 321-330

9 Makıno, S, Joo, M, and Makıno, J K A system for study of coronavırus mRNA synthesıs a regulated, expressed subgenomic defective interfering RNA results from intergenic site insertion J Virol $1991,656031-6041$

10 Makıno, S, and Joo, M Effect of intergenıc consensus sequence flankıng sequences on coronavirus transcription J Virol 1993,67 3304-3311

11 Taguchı, F, Ikeda, T, Makıno, S, and Yoshıkura, H A murıne coronavirus MHV-S isolate from persistently infected cells has a leader and two consensus sequences between the $\mathrm{M}$ and $\mathrm{N}$ genes Virology 1994,198 355-359

12 Hofmann, M A , Chang, R -Y, Ku, S, and Brian, D A Leader-mRNA junction sequences are unıque for each subgenomic mRNA species in the bovine coronavirus and remain so throughout persistent infection Virology 1993,196 163-171

13 Higuchı, R In Innıs, M A, Gelfand, D H, Snınsky, J J, White, T J (eds) PCR protocols Acadiemic Press, San Diego 1990 pp177-183

14 Makıno, S , and Laı, M M C Hıgh-frequency leader sequence switching durıng coronavirus defective interfering RNA replication J Virol 1989,63 5285-5292

15 Sambrook, J, Fritsch, E F and Maniatıs, T Molecular clonıng Cold Spring Harbor Laboratory, Cold Spring Harbor, N Y, 1989

16 Makıno, S, Shieh, C -K, Soe, L H, Baker, S C , and La1, M M C Primary structure and translation of a defective interfering RNA of murine coronavirus Virology 1988,166 550-560

17 Winship, P R An ımproved method for directly sequencıng PCR material usıng dımethyl sulfoxıde Nucleic Acids Res 1989,17 1266 